Check for updates

Cite this: RSC Adv., 2021, 11, 13848

Received 13th March 2021 Accepted 5th April 2021

DOI: 10.1039/d1ra02007b

rsc.li/rsc-advances

\title{
Poly(ethylene glycol) dimethyl ether mediated oxidative scission of aromatic olefins to carbonyl compounds by molecular oxygen $\uparrow$
}

\author{
Tao Yu, $\$$ Mingqing Guo, $\$$ Simiaomiao Wen, Rongrong Zhao, Jinlong Wang, \\ Yanli Sun, Qixing Liu* and Haifeng Zhou (D) *
}

\begin{abstract}
A simple, and practical oxidative scission of aromatic olefins to carbonyl compounds using $\mathrm{O}_{2}$ as the sole oxidant with poly(ethylene glycol) dimethyl ether as a benign solvent has been developed. A wide range of monosubstituted, gem-disubstituted, 1,2-disubstituted, trisubstituted and tetrasubstituted aromatic olefins was successfully converted into the corresponding aldehydes and ketones in excellent yields even with gram-scale reaction. Some control experiments were also conducted to support a possible reaction pathway.
\end{abstract}

\section{Introduction}

The selective oxidative scission of olefins is a practiced transformation in organic synthesis. The produced carbonyl compounds are valuable intermediates in pharmaceuticals, fragrances, agrochemicals and bulk chemical industries. ${ }^{1}$ The two-step ozonolysis is the conventional method to convert olefins into carbonyl compounds (Scheme 1a). ${ }^{2}$ In recent years, the ozone was replaced by other oxidants, such as $\mathrm{H}_{2} \mathrm{O}_{2},{ }^{3}$ oxone, ${ }^{4} \mathrm{TBHP},{ }^{5} \mathrm{~m}$-CPBA, ${ }^{6} \mathrm{KMnO}_{4},{ }^{7} \mathrm{PhIO} / \mathrm{HBF}_{4}{ }^{8}$ (Scheme 1b). However, the super stoichiometric use of expensive and toxic oxidants leads to a large amount of resource waste and environmental pollution.

Molecular oxygen is regarded as an ideal oxidant due to its easy availability, cheapness, environmental benignity and good functional-group tolerance. Recently, a series oxidative scission of olefins to carbonyl compounds with $\mathrm{O}_{2}$ as the sole oxidant, catalysed by organocatalysts NHPI, ${ }^{9} \mathrm{AIBN},{ }^{10} \mathrm{~B}_{2} \operatorname{pin}_{2},{ }^{11} \mathrm{TEMPO},{ }^{12}$ transitional-metal complexes $\mathrm{Pd},{ }^{13} \mathrm{Cu},{ }^{14} \mathrm{Fe},{ }^{15} \mathrm{Ni},{ }^{16} \mathrm{CAN},{ }^{17}$ as well as photocatalysts ${ }^{18}$ and electrocatalysts, ${ }^{19}$ have been reported (Scheme 1c). However, some shortcomings including non-commercial available catalysts, expensive additives, inevitable residual transitional-metals, and excess amount of volatile organic solvents limit their application in industry. Very recently, although a 1,2-diethoxyethane catalysed oxidative scission of olefins to ketones by air has been achieved, the

Research Center of Green Pharmaceutical Technology and Process, Hubei Key Laboratory of Natural Products Research and Development, College of Biological and Pharmaceutical Sciences, China Three Gorges University, Yichang 443002, China.E-mail: qixingliu86@163.com; zhouhf@ctgu.edu.cn

$\dagger$ Electronic supplementary information (ESI) available. See DOI: 10.1039/d1ra02007b

\$ These authors contributed equally to this work. olefins are limited to gem-disubstituted aromatic alkenes. ${ }^{20}$ Therefore, developing a wide applicable strategy for the oxidative scission of olefins to aldehydes and ketones is highly desirable but still remains a challenge.

Poly(ethylene glycol) dimethyl ether (PEGDME) has been attracting increasing interest due to its benign characteristics involving lower cost, non-volatilization, and non-toxicity, etc. ${ }^{21}$ To continue our interest in developing environmental benign synthetic reactions. ${ }^{22}$ Herein we report a simple and practical oxidative scission of a wide range of monosubstituted, gem- and 1,2-disubstituted, trisubstituted, and tetrasubstituted aromatic olefins to the corresponding aldehydes and ketones by $\mathrm{O}_{2}$ with PEGDME as a benign solvent.

(a) Traditional ozonolysis method

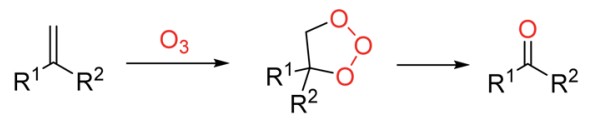

(b) Chemical oxidation method

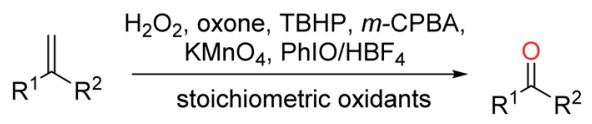

(c) Catalytic method

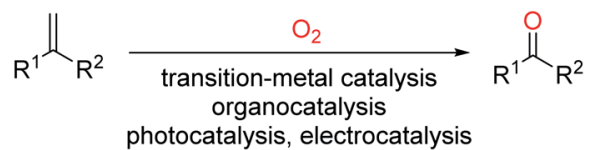

(d) This work

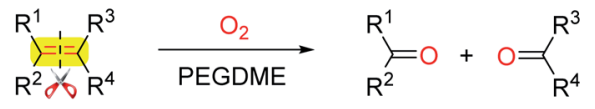

Scheme 1 Oxidative scission of olefins to carbonyl compounds. 


\section{Results and discussion}

Our studies were started with gem-diphenylethylene (1a) as a model substrate (Table 1). When the oxidation scission of 1a was performed in $N, N$-dimethylformamide (DMF), methyl tertbutyl ether (MTBE), tetrahydrofuran (THF), 2-methyltetrahydrofuran (2-MeTHF) at $130{ }^{\circ} \mathrm{C}$ or under reflux condition with $\mathrm{O}_{2}$ as the sole oxidant, only trace amount of diphenylmethanone (2a) was observed (entries 1-4). To our delight, the desired product 2 a was detected by HPLC with $73 \%$ yield in 1,4-dioxane at $100{ }^{\circ} \mathrm{C}$ for 10 hours (entry 5). However, when 1,4-dioxane was replaced by morpholine, the yield decreased to $49 \%$ (entry 6 ). To improve the reaction efficiency, ethylene glycol (EG), triethylene glycol (TEG), and a series of ethers including ethylene glycol dimethyl ether (EGDME), ethylene glycol diethyl ether (EGDEE), diethylene glycol monomethyl ether (DEGMME), diethylene glycol dimethyl ether (DEGDME), dipropylene glycol

Table 1 Optimization of the reaction conditions ${ }^{a, b}$

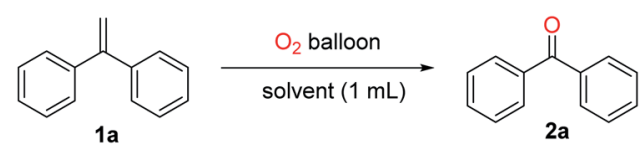

\begin{tabular}{lllll}
\hline Entry & Solvent & Temp. $\left({ }^{\circ} \mathrm{C}\right)$ & $t(\mathrm{~h})$ & Yield $^{c}(\%)$ \\
\hline 1 & DMF & 130 & 10 & $<2 \%$ \\
2 & MTBE & 55 & 10 & $<2 \%$ \\
3 & THF & 66 & 10 & $<2 \%$ \\
4 & 2-MeTHF & 78 & 10 & $<2 \%$ \\
5 & 1,4-Dioxane & 100 & 10 & 73 \\
6 & Morpholine & 130 & 10 & 49 \\
7 & EG & 130 & 10 & 54 \\
8 & TEG & 130 & 10 & 85 \\
9 & EGDME & 86 & 10 & 61 \\
10 & EGDEE & 130 & 10 & 90 \\
11 & DEGMME & 130 & 10 & 91 \\
12 & DEGDME & 130 & 10 & 93 \\
13 & DPGMME & 130 & 10 & 94 \\
14 & DPGDME & 130 & 10 & 94 \\
15 & PEG & 130 & 10 & 96 \\
16 & PEGDME & 130 & 10 & 99 \\
17 & PEGDME & 110 & 10 & 99 \\
18 & PEGDME & 100 & 10 & 78 \\
19 & PEGDME & 110 & 8 & 99 \\
20 & PEGDME & 110 & 6 & 83 \\
$21^{d}$ & PEGDME & 110 & 8 & 35 \\
$22^{e}$ & PEGDME & 110 & 8 & 64 \\
$23^{f}$ & PEGDME & 110 & 8 & 52
\end{tabular}

${ }^{a}$ Abbreviation: $N, N$-dimethylformamide (DMF), methyl tert-butyl ether (MTBE), tetrahydrofuran (THF), 2-methyltetrahydrofuran (2-MeTHF), ethylene glycol (EG), triethylene glycol (TEG), ethylene glycol dimethyl ether (EGDME), ethylene glycol diethyl ether (EGDEE), diethylene glycol monomethyl ether (DEGMME), diethylene glycol dimethyl ether (DEGDME), dipropylene glycol monomethyl ether (DPGMME), dipropylene glycol dimethyl ether (DPGDME), poly(ethylene glycol) (average $\left.M_{\mathrm{n}}, 400\right)\left(\mathrm{PEG}_{400}\right)$, poly(ethylene glycol) dimethyl ether (average $\left.M_{\mathrm{n}}, 250\right)\left(\right.$ PEGDME $\left._{250}\right){ }^{b}$ Reaction conditions: $1 \mathrm{a}(0.5 \mathrm{mmol})$, solvent $(1 \mathrm{~mL}), \mathrm{O}_{2}$ balloon. ${ }^{c}$ The yields were determined by HPLC. ${ }^{d}$ Under air atmosphere. ${ }^{e} 1 \mathrm{mmol}$ of $1 \mathrm{a} .{ }^{f} 5 \mathrm{mmol}$ of $\mathbf{1 a}$. monomethyl ether (DPGMME), and dipropylene glycol dimethyl ether (DPGDME) were screened as a solvent at $130{ }^{\circ} \mathrm{C}$ for 10 hours, providing $54-94 \%$ yields (entries $7-14$ ). Moreover, it was found that the environmentally friendly poly(ethylene glycol) (PEG) and poly(ethylene glycol) dimethyl ether (PEGDME) gave 96\% and 99\% yield, respectively (entries 15-16). Therefore, PEGDME was demonstrated to be the best solvent. Next, the effect of the reaction temperature was examined. The yield of 2a remained at $99 \%$ when the reaction temperature dropped to $110{ }^{\circ} \mathrm{C}$, but lower yield of $78 \%$ was observed at $100{ }^{\circ} \mathrm{C}$ (entries 17-18). Shorter reaction time was also attempted, the results revealed that the yield remained at $99 \%$ at 8 hours (entries 1920). When the reaction was performed under air atmosphere, the yield decreased to $35 \%$ (entry 21). In addition, it was found that the higher concentration of $\mathbf{1 a}$ led to lower yield of $\mathbf{2 a}$ (entries 22-23). Finally, the entry 19 was regarded as the optimal reaction conditions: $1 \mathrm{a}(0.5 \mathrm{mmol})$, PEGDME $(1 \mathrm{~mL})$, under $\mathrm{O}_{2}$ atmosphere, $110{ }^{\circ} \mathrm{C}$, and 8 hours.

With the optimized reaction conditions in hand, the scope of various olefins was investigated. As shown in Scheme 2, the oxidative scission of gem-diphenylethylenes bearing electrondonating group (Me, OMe) at the ortho-, meta- or para position, of the phenyl proceeded successfully to give the corresponding $2 \mathbf{b}-2 \mathrm{~g}$ with $>98 \%$ yield. In addition, the halogen element $(\mathrm{F}, \mathrm{Cl}, \mathrm{Br})$ substituted gem-diphenylethylenes were also gave corresponding ketones $2 \mathbf{h}-\mathbf{2 l}$ in $90-99 \%$ yields. The halogen substituents are useful entities amenable to further transformation in organic synthesis. The gem-diphenylethylenes with meta-substituted electron-withdrawing group $\mathrm{CF}_{3}$ gave higher yield than the ortho-substituted one (2m: 73\%, 2n: 99\%). The gem-diphenylethylenes with two or three substituents on the phenyls also gave the desired products 2o$2 \mathbf{u}$ in $86-99 \%$ yields. When phenyl of gem-diphenylethylene was replaced by naphthyl, thienyl and pyridyl, the oxidative scission also proceeded smoothly, affording the corresponding products $2 \mathbf{v}-2 \mathbf{x}$ in $60-95 \%$ yields. To our delighted, the substrates containing fluorene or thioxanthene moiety also provided the desired ketones $2 \mathbf{y}$ and $2 \mathrm{z}$ in $87 \%$ and $85 \%$ yields. Furthermore, the aryl-alkyl disubstituted olefins like $\alpha$-methylstyrene and $\alpha$ cyclopropylstyrene were also applicable to this oxidative scission. The corresponding ketones $\mathbf{2} \mathbf{a a}$ and $\mathbf{2} \mathbf{a b}$ were obtained in $99 \%$ and $93 \%$ yields.

Aldehydes are also important building blocks in fine chemicals. And then, we examined this oxidative scission of olefins to prepare aldehydes. As shown in Scheme 3, the monosubstituted, 1,2-disubstituted, trisubstituted and tetrasubstituted aromatic olefins were also subjected to this transformation. For example, the monosubstituted aromatic olefine 1ac was cleavaged to give 4-bromobenzaldehyde (2ac) in $92 \%$ yield under standard conditions. Benzaldehyde 2 ad was obtained as the sole product in $95 \%$ yield by the oxidative scission of 1,2-disubstituted aromatic olefine 1ad. Interestingly, the 1,4-bis(2-methylstyryl)benzene (1ae) can be cleavaged to 1,4phthalaldehyde (2ae) and 2-methylbenzaldehyde (2ae') in $83 \%$ and $82 \%$ yield. When trisubstituted 1,1-diphenyl-2-(4bromophenyl)ethene (1af) and triphenylethylene (1ag) were used as substrates, the corresponding products 4- 


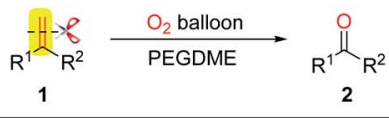

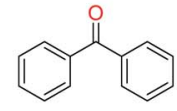

2a: $99 \%$ yield<smiles>Cc1ccc(C(=O)c2ccccc2)cc1</smiles>

2d: $98 \%$ yield<smiles>COc1ccc(C(=O)c2ccccc2)cc1</smiles>

2g: $99 \%$ yield<smiles>O=C(c1ccccc1)c1ccccc1Cl</smiles>

2j: $91 \%$ yield<smiles>O=C(c1ccccc1)c1ccccc1C(F)(F)F</smiles>

2m: $73 \%$ yield

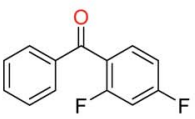

2p: $90 \%$ yield

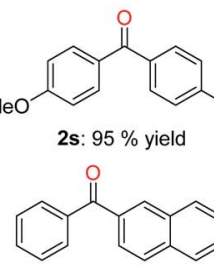

2v: $81 \%$ yield

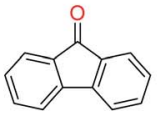

2y: $87 \%$ yield

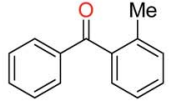

2b: $98 \%$ yield<smiles>COc1ccccc1C(=O)c1ccccc1</smiles>

2e: $99 \%$ yield<smiles>O=C(c1ccccc1)c1ccccc1F</smiles>

2h: $91 \%$ yield<smiles>O=C(c1ccccc1)c1ccc(Cl)cc1</smiles>

2k: $97 \%$ yield<smiles>O=C(c1ccccc1)c1cccc(C(F)(F)F)c1</smiles>

2n: $99 \%$ yield

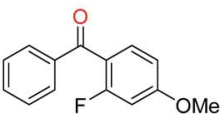

2q: $90 \%$ yield

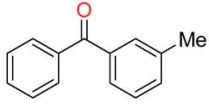

2c: $98 \%$ yield<smiles>COc1cccc(C(=O)c2ccccc2)c1</smiles>

2f: $98 \%$ yield<smiles>O=C(c1ccccc1)c1ccc(F)cc1</smiles>

2i: $99 \%$ yield

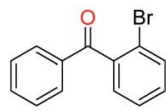

2l: $90 \%$ yield

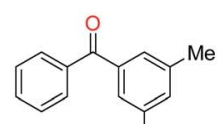

2o: $99 \%$ yield $\mathrm{Me}$

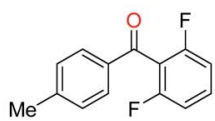

2r: $86 \%$ yield<smiles>[Y]c1cc(C)cc(C(=O)c2ccc(C(F)(F)F)cc2)c1</smiles>

2t: $97 \%$ yield $\quad 2 u$ : $99 \%$ yield $\mathrm{Me}$

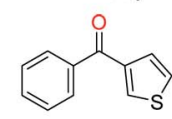

2w: $60 \%$ yield

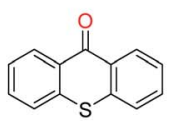

2z: $85 \%$ yield

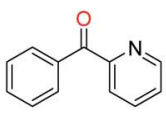

2x: $95 \%$ yield

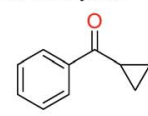

2aa: $99 \%$ yield 2 ab: $93 \%$ yield
Scheme 2 Scope of gem-disubstituted aromatic olefins. Reaction conditions: 1 ( $0.5 \mathrm{mmol}), \mathrm{PEGDME}(1 \mathrm{~mL}), \mathrm{O}_{2}$ balloon, $110^{\circ} \mathrm{C}, 8$ hours, isolated yield.

bromobenzaldehyde (2ac), benzaldehyde (2ad) and diphenylmethanone (2a) were obtained in about $90 \%$ yields. Finally, the tetraphenylethylene (1ah) was also subjected to this oxidative scission, less than $5 \%$ yield was obtained even if elevating the temperature to $150{ }^{\circ} \mathrm{C}$ and extending the reaction time to 24 hours.

To understand the reaction pathway, control experiments were conducted. As shown in Scheme 4, when the oxidative scission of gem-diphenylethylene (1a) was carried out under $\mathrm{N}_{2}$ atmosphere, no product 2a was observed. Only a trace amount of oxidation product $2 \mathrm{a}$ was detected in the presence of a radical scavenger 2,2,6,6-tetramethylpiperidine- $N$-oxyl (TEMPO) under

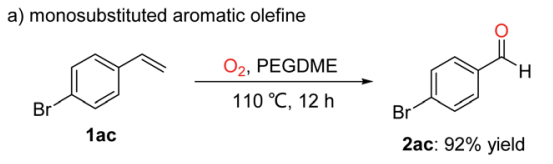

b) 1,2-disubstituted aromatic olefines
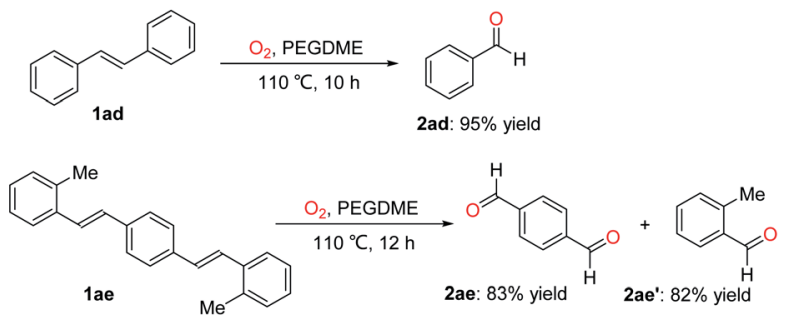

c) trisubstituted aromatic olefines
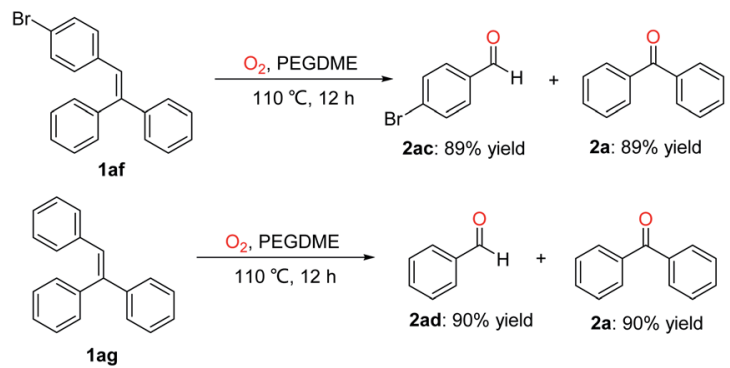

d) tetrasubstituted aromatic olefine

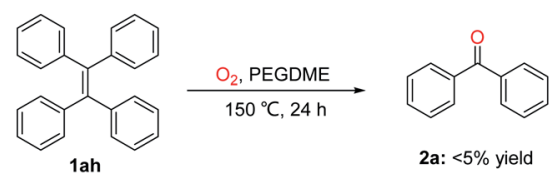

Scheme 3 Scope of mono, di-, tri-, and tetrasubstituted aromatic olefins.

optimal conditions. It means that a radical reaction pathway might be involved. When 2,2-diphenyloxirane (3a) was used as the starting material, the desired ketone 2 a could be obtained in 99\% yield, indicating that 3a might be a key intermediate of this oxidative scission reaction.

Based on the control experiments and reported work, ${ }^{20}$ a plausible reaction pathway was proposed as shown in Scheme 5. Firstly, PEGDME was oxidized by $\mathrm{O}_{2}$ to produce a peroxyl

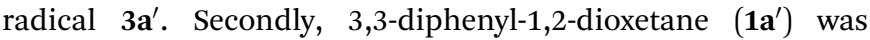
formed by the oxidation of gem-diphenylethylene (1a) with $\mathbf{3} \mathbf{a}^{\prime}$ as<smiles>C=C(c1ccccc1)c1ccccc1</smiles>

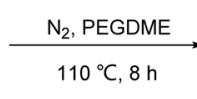

ii)

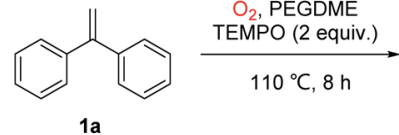

iii)

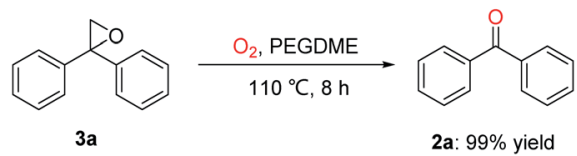

Scheme 4 Control experiments. 


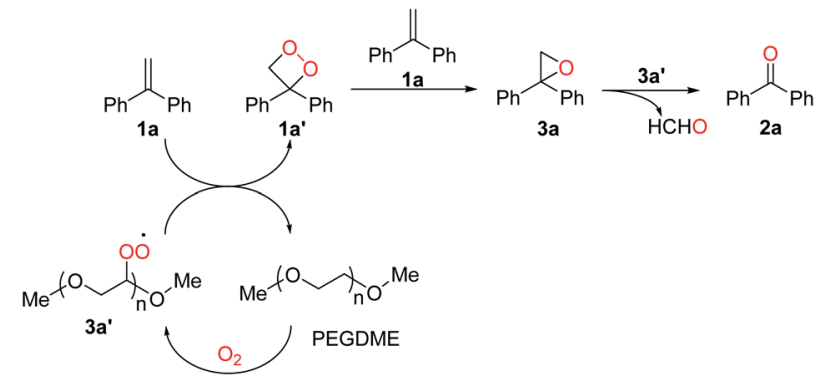

Scheme 5 Plausible reaction pathway.

an oxidant, regenerating PEGDME concurrently. And then, 1a' is converted to the more stable key intermediate 2,2-diphenyloxirane (3a) with one equivalent of 1a. Finally, 3a was converted to give the product $\mathbf{2 a}$ with $\mathbf{3} \mathbf{a}^{\prime}$ as an oxidant.

To further demonstrate the practicality of this oxidative scission reaction, as shown in Scheme 6, a gram-scale reaction of gem-diphenylethylene (1a; $1.80 \mathrm{~g}, 10 \mathrm{mmol}$ ) was conducted under $\mathrm{O}_{2}$ atmosphere in PEGDME at $110{ }^{\circ} \mathrm{C}$ for 10 hours, the product diphenylmethanone (2a) was isolated in 96\% yield (1.75 g).

\section{Conclusions}

In summary, we have developed an oxidative scission of aromatic olefins to carbonyl compounds using molecular oxygen as the sole oxidant with PEGDME as solvent. A wide range of monosubstituted, gem- and 1,2-disubstituted, trisubstituted, and tetrasubstituted aromatic olefins were oxidized to aldehydes and ketones in excellent yields. A reaction pathway was proposed based on some control experiments. A successful gram-scale reaction also demonstrated its practicability.

\section{Experimental section}

\section{General information}

Unless otherwise noted, all reagents, catalysts and solvents were purchased from commercial suppliers and used without further purification. Column chromatography was performed with silica gel (200-300 mesh). NMR spectra were recorded on Bruker AVANCE III (400 MHz) spectrometers. $\mathrm{CDCl}_{3}$ was the solvent used for the NMR analysis, with tetramethyl silane as an internal standard. Chemical shifts were reported up field to TMS (0.00 ppm) for ${ }^{1} \mathrm{H}$ NMR and relative to $\mathrm{CDCl}_{3}(77.0 \mathrm{ppm})$ for ${ }^{13} \mathrm{C}$ NMR. HPLC analysis was conducted on an Agilent 1200 Series instrument with 5C18-MS-II Packed Column (4.6 mm I.D. $\times 250 \mathrm{~mm})$.

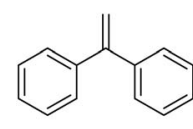

1a: $1.80 \mathrm{~g}$

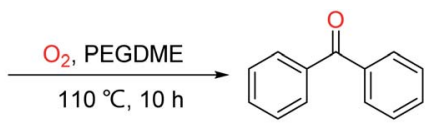

2a $1.75 \mathrm{~g}, 96 \%$ yield
General procedure for oxidation scission of aromatic olefin

The corresponding aromatic olefin 1 (0.5 mmol), PEGDME (1 $\mathrm{mL}$ ) were added to a $10 \mathrm{~mL}$ Schlenk tube. The tube was evacuated and filled with oxygen three times. The mixture was stirred at $110{ }^{\circ} \mathrm{C}$ for 8 hours under $\mathrm{O}_{2}$ atmosphere using a balloon. After cooling, the mixture was subjected to silica gel column chromatography (PE : EA = $15: 1)$ to give the product 2 .

\section{Gram-scale oxidation scission of gem-diphenylethylene (1a)}

The gem-diphenylethylene (1a, $1.80 \mathrm{~g}, 10 \mathrm{mmol})$, PEGDME (20 $\mathrm{mL}$ ) were added to a $50 \mathrm{~mL}$ of round-bottomed flask equipped with a three-way jointer. The flask was then evacuated and filled with oxygen three times. The mixture was stirred at $110^{\circ} \mathrm{C}$ for 10 hours under $\mathrm{O}_{2}$ atmosphere using a balloon. After cooling, the mixture was subjected to silica gel column chromatography $(\mathrm{PE}: \mathrm{EA}=15: 1)$ to give the product $2 \mathrm{a}(1.75 \mathrm{~g}, 96 \%$ yield $)$.

\section{Conflicts of interest}

There are no conflicts to declare.

\section{Acknowledgements}

This work was supported by the 111 Project (D20015) and the Natural Science Foundation of Hubei Province of China (2018CFB241).

\section{Notes and references}

1 (a) M. B. Smith and J. March, Advanced Organic Chemistry, Wiley-VCH, New York, 2007; (b) J. E. Backvall, Modern Oxidation Methods, Wiley-VCH, New York, 2004; (c) R. C. Larock, Comprehensive Organic Transformations, 2nd edn, Wiley-VCH, New York, 1999; (d) F. Puls and H. J. Knolker, Angew. Chem., Int. Ed., 2018, 57, 1222; (e) N. E. Thornburg, A. B. Thompson and J. M. Notestein, ACS Catal., 2015, 5, 5077; ( $f$ ) A. Kumar, A. K. Gupta, M. Devi, K. E. Gonsalves and C. P. Pradeep, Inorg. Chem., 2017, 56, 10325.

2 (a) R. Criegee, Angew. Chem., Int. Ed., 1975, 14, 745; (b) A. J. Kendall, J. T. Barry, D. T. Seidenkranz, A. Ryerson, C. Hiatt, C. A. Salazar, D. J. Bryant and D. R. Tyler, Tetrahedron Lett., 2016, 57, 1342; (c) T. J. Fisher and P. H. Dussault, Tetrahedron, 2017, 73, 4233; (d) S. G. V. Ornum, R. M. Champeau and R. Pariza, Chem. Rev., 2006, 106, 2990.

3 (a) W. Yu and Z. Zhao, Org. Lett., 2019, 21, 7726; (b) C. P. Yap, J. K. Ng, S. Madrahimov, A. A. Bengali, T. S. Chwee and W. Y. Fan, New J. Chem., 2018, 42, 11131; (c) T. Wang, X. Jing, C. Chen and L. Yu, J. Org. Chem., 2017, 82, 9342.

4 (a) J. N. Moorthy and K. N. Parida, J. Org. Chem., 2015, 79, 11431; (b) D. Yang and C. Zhang, J. Org. Chem., 2001, 66, 4814 .

5 (a) D. J. Lippincott, P. J. Trejo-Soto, F. Gallou and B. H. Lipshutz, Org. Lett., 2018, 20, 5094; (b) M. M. Hossain, W. Huang, H. J. Chen, P. Wang and 
S. G. Shyu, Green Chem., 2014, 16, 3013; (c) D. Xing, B. Guan, G. Cai, Z. Fang, L. Yang and Z. Shi, Org. Lett., 2006, 8, 693.

6 F. V. Singh, H. M. S. Milagre, M. N. Eberlin and H. A. Stefani, Tetrahedron Lett., 2009, 50, 2312.

7 S. Lai and D. G. Lee, Synthesis, 2001, 11, 1645.

8 K. Miyamoto, N. Tada and M. Ochiai, J. Am. Chem. Soc., 2007, 129, 2772.

9 R. Lin, F. Chen and N. Jiao, Org. Lett., 2012, 14, 4158.

10 G. Wang, X. Li, J. Dai and H. Xu, J. Org. Chem., 2014, 79, 7220.

11 Z. Cheng, W. Jin and C. Liu, Org. Chem. Front., 2019, 6, 841. 12 T. Wang and N. Jiao, J. Am. Chem. Soc., 2013, 135, 11692.

13 (a) C. A. Hone, A. O'Kearney-McMullan, R. Munday and C. O. Kappe, ChemCatChem, 2017, 9, 3298; (b) A. Wang and H. Jiang, J. Org. Chem., 2010, 75, 2321; (c) B. Feng, Z. Hou, X. Wang, Y. Hu, H. Li and Y. Qiao, Green Chem., 2009, 11, 1446.

14 (a) Y. Liu, D. Xue, C. Li, J. Xiao and C. Wang, Catal. Sci. Technol., 2017, 7, 5510; (b) M. M. Hossain and S. G. Shyu, Tetrahedron, 2014, 70, 251; (c) M. Tokunaga, Y. Shirogane, H. Aoyama, Y. Obora and Y. Tsuji, J. Organomet. Chem., 2005, 690, 5378.

15 (a) B. Xiong, X. Zeng, S. Geng, S. Chen, Y. He and Z. Feng, Green Chem., 2018, 20, 4521; (b) A. Toru and F. Hayato, Tetrahedron Lett., 2018, 59, 2657; (c) A. Gonzalez-De-Castro and J. Xiao, J. Am. Chem. Soc., 2015, 137, 8206.

16 G. Urgoitia, R. SanMartin, M. T. Herrero and E. Domínguez, Adv. Synth. Catal., 2016, 358, 1150.

17 L. Yu, Y. Huang, Z. Bai, B. Zhu, K. Ding, T. Chen, Y. Ding and Y. Wang, J. Chin. Chem. Soc., 2015, 62, 479.
18 (a) S. S. Han, J. Y. Park, H. S. Hwang, H. R. Choe, K. M. Nam and E. J. Cho, ChemSusChem, 2019, 12, 3018; (b) K. Ohkubo, T. Nanjo and S. Fukuzumi, Org. Lett., 2005, 7, 4265; (c) Y. Ren, Y. Che, W. Ma, X. Zhang, T. Shen and J. Zhao, New J. Chem., 2004, 28, 1464; (d) Y. Deng, X. Wei, H. Wang, Y. Sun, T. Noel and X. Wang, Angew. Chem., Int. Ed., 2017, 56, 832.

19 Y. Imada, Y. Okada, K. Noguchi and K. Chiba, Angew. Chem., Int. Ed., 2019, 58, 125.

20 K. Liu, J. Deng, T. Zeng, X. Chen, Y. Huang, Z. Cao, Y. Lin and W. He, Chin. Chem. Lett., 2020, 31, 1868.

21 (a) L. J. Xu, K. H. Lam, J. X. Ji, J. Wu, Q. H. Fan, W. H. Lo and A. S. C. Chan, Chem. Commun., 2005, 1390; (b) H. F. Zhou, Q. H. Fan, Y. M. He, L. Q. Qu and A. S. C. Chan, Prog. Chem., 2009, 17, 1517; (c) S. J. Ha, E.-Y. Jung, W. M. Kim and J. C. Lee, Bull. Korean Chem. Soc., 2014, 35, 629; (d) K. J. Liu, J. H. Deng, J. Yang, S. F. Gong, Y. W. Lin, J. Y. He, Z. Cao and W. M. He, Green Chem., 2020, 22, 433.

22 (a) H. F. Zhou, Q. H. Fan, W. J. Tang, L. J. Xu, Y. M. He, G. J. Deng, L. W. Zhao, L. Q. Gu and A. S. C. Chan, Adv. Synth. Catal., 2006, 348, 2172; (b) H. F. Zhou, Q. H. Fan, Y. Y. Huang, L. Wu, Y. M. He, W. J. Tang, L. Q. Gu and A. S. C. Chan, J. Mol. Catal. A: Chem., 2007, 275, 47; (c) H. Zhou, Z. Li, Z. Wang, T. Wang, L. Xu, Y. He, Q. H. Fan, J. Pan, L. Gu and A. S. C. Chan, Angew. Chem., Int. Ed., 2008, 47, 8464; (d) P. Cui, Q. Liu, J. Wang, H. Liu and H. Zhou, Green Chem., 2019, 21, 634; (e) B. Yang, P. Cui, Y. Chen, Q. Liu and H. Zhou, Tetrahedron Lett., 2020, 61, 152530 . 